\title{
Results II
}

In this Results II section, we look separately at OCOG revenue and expenditure categories and also at the individual venues in the non-OCOG budgets. To do so, we first separate the data by distinguishing between the Olympic Games and the Olympic Winter Games. We display for each category the minimum and maximum final deviations from the projected budget to the final budget and its evolution. We added a line representing the average development of the category for the respective five Olympic Games/Olympic Winter Games. Thus, the following graphs show a so-called "uncertainty corridor". The bigger the corridor is, the higher the uncertainty about cost and revenue development. Strong fluctuations in the mean value result mostly from the lack of values at a given time.

\subsection{Revenue Corridors by OCOG Category}

First we will look at the Olympic Games and Olympic Winter Games revenues that were received by the respective OCOGs.

The IOC contribution supports the staging of the Games. This includes direct contribution to the OCOGs (through the share of the television broadcasting rights and TOP rights, support of the OCOG in transfer-of-knowledge activities and expertise to the organisers). From the 2010 Games in Vancouver onwards, the IOC has funded the host broadcaster operations, Olympic Broadcasting Services. These costs were

(C) The Author(s) 2019

$\mathrm{H}$. Preuß et al., Cost and Revenue Overruns of the Olympic

Games 2000-2018, Event- und Impaktforschung,

https://doi.org/10.1007/978-3-658-24996-0_5 
previously borne by the OCOGs. In addition to this funding, the IOC continues to provide a contribution to the operations of the organising committee. Until Beijing, the IOC contribution was paid as a percentage of revenue from the sale of TV rights. That means the amounts can fluctuate very much and depend on for how much money the TV rights were sold. In addition, exchange rates and the rate of inflation affects the amount actually paid. From Vancouver onwards, an absolute amount was fixed before the application phase. This means that this amount was deflated down to the application year. One reason may be that an incorrect estimated inflation rate has been used. Furthermore, the exchange rate is again an influencing factor.

Table 47 Olympic Games estimated and final revenues - IOC contribution

\begin{tabular}{lllllllllll}
\hline $\begin{array}{l}\text { IOC } \\
\text { Contribution }\end{array}$ & $\mathbf{t}-\mathbf{8}$ & $\mathbf{t}-\mathbf{6}$ & $\mathbf{t}-\mathbf{5}$ & $\mathbf{t}-\mathbf{4}$ & $\mathbf{t}-\mathbf{3}$ & $\mathbf{t}-\mathbf{2}$ & $\mathbf{t}-\mathbf{1}$ & final & \\
\hline & & & & & & & & & \\
\hline & Max & $0 \%$ & $-8 \%$ & & & $24 \%$ & $32 \%$ & $32 \%$ & $41 \%$ & SYDNEY \\
\cline { 2 - 10 } & Min & $0 \%$ & & & & & & $-15 \%$ & $-25 \%$ & BEIJING \\
\hline & Max & $0 \%$ & $34 \%$ & & $36 \%$ & $28 \%$ & & & $23 \%$ & SALT LAKE \\
\hline
\end{tabular}

Sources: Athens 2004 Olympic Bid Committee (1996); ATHOC (2003, 2004, 2005a, b); Beijing 2008 Olympic Games Bid Committee (2001); BOCOG (n. d., 2007); COJOPR (2015, 2016a, b); IOC Data; LOCOG (2008, 2009 2012); London 2012 Candidate City (2004); OCA (2002); Rio 2016 Candidate City (2008); Sydney Olympics Bid 2000 (1993); SOCOG (1994, 2001, 2002); POCOG (2014, 2016, 2018); PyeongChang 2018 Olympic \& Paralympic Winter Games Bid Committee (2010); Salt Lake City Bid Committee (1994); SLOC (n. d., 2002); Sochi 2014 Bid Committee (2006); SOOC (2011, 2012, 2013, 2014); Torino Bid Committee (1998); TOROC (2005); Vancouver 2010 Candidate City (2002); VANOC (2007, 2008, 2009, 2014)

SUMMER: The IOC contribution to the hosts of the Olympic Games varies from a maximum revenue overrun in Sydney (41\%) to a revenue underrun in Beijing (-25\%). From Sydney 2000 to Beijing 2008, the OCOGs received an IOC contribution that was dependent on the income from the sale of TV rights. The new regulation, which describes a fixed amount from the signing of the Host City Contract, seems to better assess revenue. This shows that London 2012 and Rio 2016 are not among the extremes. What we observe here is the effect of exchange rates and inflation. It is important to note here that the changes are not based on a better or worse payment from the IOC, but on the economic situation. Nevertheless, we can state that the mean revenues from the IOC contribution produced a revenue overrun of $4 \%$. 
WINTER: The IOC contribution was larger than expected for three Games, though two cities had less. Due to strong inflation, Sochi 2014 received 32\% (in value) less than announced eight years before. This is offset by positive changes, such as in Salt Lake City 2002 with an increase of $23 \%$. Despite this, on average, the host cities received $12 \%$ less IOC contribution for the Olympic Winter Games.

Revenues from TOP rights are partly received in cash, in which case they are recorded in the period the instalments become due, and partly received in the form of goods or services (Value in Kind). Value in Kind is recognised for the USOC, the NOCs and the IOC on a linear basis during the period of the contract. However, for the OCOGs the money is paid only in the year of the Games (IOC 2014, 133).

Table 48 Olympic Games estimated and final revenues - TOP sponsorship

\begin{tabular}{|c|c|c|c|c|c|c|c|c|c|c|}
\hline \multicolumn{2}{|c|}{$\begin{array}{l}\text { TOP } \\
\text { Sponsorship }\end{array}$} & $t-8$ & $t-6$ & $t-5$ & $t-4$ & $t-3$ & $t-2$ & $t-1$ & final & \\
\hline \multirow{3}{*}{ 离 } & $\operatorname{Max}$ & $0 \%$ & & & $156 \%$ & $162 \%$ & $154 \%$ & $145 \%$ & $117 \%$ & ATHENS \\
\hline & Mean & $0 \%$ & $-8 \%$ & $-7 \%$ & $46 \%$ & $53 \%$ & $76 \%$ & $60 \%$ & $60 \%$ & \\
\hline & Min & $0 \%$ & & $-7 \%$ & $-5 \%$ & $-5 \%$ & & $8 \%$ & $19 \%$ & LONDON \\
\hline \multirow{3}{*}{ 离 } & Max & $0 \%$ & $95 \%$ & & $94 \%$ & $57 \%$ & & & $72 \%$ & SALT LAKE \\
\hline & Mean & $0 \%$ & $95 \%$ & & $43 \%$ & $9 \%$ & $-5 \%$ & $25 \%$ & $11 \%$ & \\
\hline & Min & $0 \%$ & & & & $-44 \%$ & $-51 \%$ & $-54 \%$ & $-45 \%$ & SOCHI \\
\hline
\end{tabular}

Sources: Athens 2004 Olympic Bid Committee (1996); ATHOC (2003, 2004, 2005a, b); Beijing 2008 Olympic Games Bid Committee (2001); BOCOG (n. d., 2007); COJOPR (2015, 2016a, b); IOC Data; LOCOG (2008, 2009 2012); London 2012 Candidate City (2004); OCA (2002); Rio 2016 Candidate City (2008); Sydney Olympics Bid 2000 (1993); SOCOG (1994, 2001, 2002); POCOG (2014, 2016, 2018); PyeongChang 2018 Olympic \& Paralympic Winter Games Bid Committee (2010); Salt Lake City Bid Committee (1994); SLOC (n. d., 2002); Sochi 2014 Bid Committee (2006); SOOC (2011, 2012, 2013, 2014); Torino Bid Committee (1998); TOROC (2005); Vancouver 2010 Candidate City (2002); VANOC (2007, 2008, 2009, 2014)

SUMMER: It is easy to see that there has always been a revenue overrun from TOP sponsorship. This illustrates the ongoing success of Olympic marketing. However, in future this revenue source will also be more stable because the IOC now includes the formerly separately paid TOP sponsorship in its IOC contribution. This gives more security to the bid cities, but removes any opportunity to obtain more money or, on the other hand, to lose money. The figure shows that Athens 2004 received almost twice the money than that was planned in its bid book, while London 2012 received only $19 \%$ more. From 2000 to 2016, the five Games average was an additional $60 \%$. 
WINTER: The TOP Programme generated an average $11 \%$ more revenues. The maximum increase in revenue of $72 \%$ was achieved for Salt Lake City 2002 as TOP Partners had signed for higher values in 2002. Sochi 2014 was the only host city with a $45 \%$ revenue underrun (mainly due to currency and inflation impact, which changed the final revenues value).

The OCOGs also raise additional revenue through domestic commercial activities facilitated by the authorised use of the Olympic marks together with the OCOGs' symbols.

Table 49 Olympic Games estimated and final revenues - national sponsorship

\begin{tabular}{|c|c|c|c|c|c|c|c|c|c|c|}
\hline \multicolumn{2}{|c|}{$\begin{array}{l}\text { National } \\
\text { Sponsorship }\end{array}$} & $t-8$ & $t-6$ & $t-5$ & $t-4$ & $t-3$ & $t-2$ & $t-1$ & final & \\
\hline \multirow{3}{*}{ 总 } & $\operatorname{Max}$ & $0 \%$ & & & & & & $507 \%$ & $382 \%$ & BEIJING \\
\hline & Mean & $0 \%$ & $-1 \%$ & $36 \%$ & $55 \%$ & $64 \%$ & $67 \%$ & $140 \%$ & $123 \%$ & \\
\hline & Min & $0 \%$ & & & $-15 \%$ & $-1 \%$ & $0 \%$ & $-4 \%$ & $16 \%$ & ATHENS \\
\hline \multirow{3}{*}{ 离 } & $\operatorname{Max}$ & $0 \%$ & & & & $97 \%$ & $69 \%$ & $72 \%$ & $76 \%$ & SOCHI \\
\hline & Mean & $0 \%$ & $95 \%$ & & $65 \%$ & $59 \%$ & $47 \%$ & $71 \%$ & $59 \%$ & \\
\hline & Min & $0 \%$ & & & & $42 \%$ & $36 \%$ & $39 \%$ & $30 \%$ & VANCOUVER \\
\hline
\end{tabular}

Sources: Athens 2004 Olympic Bid Committee (1996); ATHOC (2003, 2004, 2005a, b); Beijing 2008 Olympic Games Bid Committee (2001); BOCOG (n. d., 2007); COJOPR (2015, 2016a, b); IOC Data; LOCOG (2008, 2009 2012); London 2012 Candidate City (2004); OCA (2002); Rio 2016 Candidate City (2008); Sydney Olympics Bid 2000 (1993); SOCOG (1994, 2001, 2002); POCOG (2014, 2016, 2018); PyeongChang 2018 Olympic \& Paralympic Winter Games Bid Committee (2010); Salt Lake City Bid Committee (1994); SLOC (n. d., 2002); Sochi 2014 Bid Committee (2006); SOOC (2011, 2012, 2013, 2014); Torino Bid Committee (1998); TOROC (2005); Vancouver 2010 Candidate City (2002); VANOC (2007, 2008, 2009, 2014)

SUMMER: The revenue from the national sponsorship programmes was also a success story for all Olympic Games. The highest increase of revenues was for Beijing 2008. The revenue from national sponsorship increased by $382 \%$. This can be explained by sponsorship by semi-governmental organisations and a higher number of sponsorships. Between t-2 and t-1, Beijing managed to increase the number of sponsorships by 29 (Södermann \& Dolles 2010, 15). Athens, with the lowest revenue overrun, also posted a revenue growth of $16 \%$. The average development of national sponsorship revenues is more than double of what was projected in the candidature files. 
WINTER: Here, all Games have achieved more than projected. Sochi 2014 had the highest revenue overrun of 76\%, while the lowest was Vancouver 2010 with 30\%. Ultimately, on average, about $59 \%$ more was reached by Olympic Winter Games hosts.

An essential component of the income of the organising committees is the sale of tickets.

Table 50 Olympic Games estimated and final revenues - ticket sales

\begin{tabular}{|c|c|c|c|c|c|c|c|c|c|c|}
\hline \multicolumn{2}{|c|}{ Ticket Sales } & $t-8$ & $t-6$ & $t-5$ & $t-4$ & $t-3$ & $t-2$ & $t-1$ & final & \\
\hline \multirow{3}{*}{ 离 } & Max & $0 \%$ & $-8 \%$ & & & $122 \%$ & $170 \%$ & $173 \%$ & $166 \%$ & SYDNEY \\
\hline & Mean & $0 \%$ & $-8 \%$ & $15 \%$ & $35 \%$ & $36 \%$ & $59 \%$ & $47 \%$ & $63 \%$ & \\
\hline & Min & $0 \%$ & & & & & & $-24 \%$ & $-22 \%$ & BEIJING \\
\hline \multirow{3}{*}{ 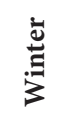 } & Max & $0 \%$ & $44 \%$ & & $18 \%$ & $100 \%$ & & & $112 \%$ & SALT LAKE \\
\hline & Mean & $0 \%$ & $44 \%$ & & $-11 \%$ & $2 \%$ & $-22 \%$ & $-4 \%$ & $32 \%$ & \\
\hline & Min & $0 \%$ & & & & $-37 \%$ & & $-6 \%$ & $-15 \%$ & SOCHI \\
\hline
\end{tabular}

Sources: Athens 2004 Olympic Bid Committee (1996); ATHOC (2003, 2004, 2005a, b); Beijing 2008 Olympic Games Bid Committee (2001); BOCOG (n. d., 2007); COJOPR (2015, 2016a, b); IOC Data; LOCOG (2008, 2009 2012); London 2012 Candidate City (2004); OCA (2002); Rio 2016 Candidate City (2008); Sydney Olympics Bid 2000 (1993); SOCOG (1994, 2001, 2002); POCOG (2014, 2016, 2018); PyeongChang 2018 Olympic \& Paralympic Winter Games Bid Committee (2010); Salt Lake City Bid Committee (1994); SLOC (n. d., 2002); Sochi 2014 Bid Committee (2006); SOOC (2011, 2013, 2014); Torino Bid Committee (1998); Vancouver 2010 Candidate City (2002); VANOC (2007, 2008, 2009, 2014)

SUMMER: Beijing 2008 was the only Olympic Games that generated less from ticket sales than projected during the bid. All other hosts were extremely successful in selling their tickets. Sydney 2000 recorded the highest revenue overrun with $166 \%$. On average, host cities between 2000 and 2016 had an increase of around $63 \%$.

WINTER: Estimating the revenues from ticketing is difficult. Salt Lake City 2002 earned 112\% more revenue than estimated, but PyeongChang 2018 had a loss of $42 \%$. Sochi 2014 also had smaller revenues than expected. On average, about 32\% more revenues were achieved for tickets at the Olympic Winter Games. Factors besides a good or bad estimate that may influence ticket sales are later decisions on the higher capacity of venues, new events staged in the same venues, fewer visitors coming or different ticket prices than calculated before. 
The licensing category includes the sale of merchandise items as well as stamps and coins. Licensing agreements will include a royalty advance and a minimum guarantee. The advance is a non-refundable deposit for the licensing rights, while the guarantee is the minimum amount a licensee will pay, against which royalties may be offset.

Table 51 Olympic Games estimated and final revenues - licensing

\begin{tabular}{llllrrrrrl}
\hline Licensing & $\mathbf{t}-\mathbf{8}$ & $\mathbf{t}-\mathbf{6}$ & $\mathbf{t}-\mathbf{5}$ & $\mathbf{t}-\mathbf{4}$ & $\mathbf{t}-\mathbf{3}$ & $\mathbf{t}-\mathbf{2}$ & $\mathbf{t}-\mathbf{1}$ & $\mathbf{f i n a l}$ & \\
\hline Max & $0 \%$ & & & & & & $26 \%$ & $66 \%$ & BEIJING \\
\hline Mean & $0 \%$ & $-8 \%$ & $11 \%$ & $6 \%$ & $2 \%$ & $3 \%$ & $16 \%$ & $26 \%$ & \\
\hline Min & $0 \%$ & $-8 \%$ & & & $-24 \%$ & $-20 \%$ & $-23 \%$ & $-14 \%$ & SYDNEY \\
\hline Max & $0 \%$ & & & & $3 \%$ & $16 \%$ & $19 \%$ & $25 \%$ & VANCOUVER \\
\hline Mean & $0 \%$ & $8 \%$ & & $-2 \%$ & $17 \%$ & $57 \%$ & $61 \%$ & $-9 \%$ & \\
\hline Min & $0 \%$ & $8 \%$ & & $15 \%$ & $-41 \%$ & & & $-28 \%$ & SALT LAKE \\
\hline
\end{tabular}

Sources: Athens 2004 Olympic Bid Committee (1996); ATHOC (2003, 2004, 2005a, b); Beijing 2008 Olympic Games Bid Committee (2001); BOCOG (n. d., 2007); COJOPR (2015, 2016a, b); IOC Data; LOCOG (2008, 2009 2012); London 2012 Candidate City (2004); OCA (2002); Rio 2016 Candidate City (2008); Sydney Olympics Bid 2000 (1993); SOCOG (1994, 2001, 2002); POCOG (2014, 2016, 2018); PyeongChang 2018 Olympic \& Paralympic Winter Games Bid Committee (2010); Salt Lake City Bid Committee (1994); SLOC (n. d., 2002); Sochi 2014 Bid Committee (2006); SOOC (2011, 2012, 2013, 2014); Torino Bid Committee (1998); TOROC (2005); Vancouver 2010 Candidate City (2002); VANOC (2007, 2008, 2009, 2014)

SUMMER: Revenues from licencing are difficult to predict. It depends on the sales at Games time. Licensing revenues had an average revenue increase of $26 \%$. Beijing 2008 had the highest revenue overrun (66\%) while Sydney 2000 overestimated its revenues. We will see later that Salt Lake City 2002 also generated smaller revenues than expected during the bid. This shows that this category is one of the most difficult to predict.

WINTER: The spectrum of changes is also large. On average, a revenue underrun of $9 \%$ was recorded. The maximum additional revenue was achieved in Vancouver (25\%). Sochi 2014 and Salt Lake City 2002 were unable to reach their initial estimates, with Salt Lake City having revenue underruns of $28 \%$. 
Table 52 Olympic Games estimated and final revenues - lotteries

\begin{tabular}{lccccccccc}
\hline Lotteries & $\mathbf{t}-\mathbf{8}$ & $\mathbf{t}-\mathbf{6}$ & $\mathbf{t}-\mathbf{5}$ & $\mathbf{t}-\mathbf{4}$ & $\mathbf{t}-\mathbf{3}$ & $\mathbf{t}-\mathbf{2}$ & $\mathbf{t}-\mathbf{1}$ & $\mathbf{f i n a l}$ & \\
\hline $\begin{array}{l}\text { Olympic } \\
\text { Games }\end{array}$ & $0 \%$ & & & $21 \%$ & $17 \%$ & $14 \%$ & $10 \%$ & $28 \%$ & ATHENS \\
\hline $\begin{array}{l}\text { Olympic } \\
\text { Winter Games }\end{array}$ & $0 \%$ & & & & $91 \%$ & $75 \%$ & & & SOCHI \\
\hline
\end{tabular}

Sources: Athens 2004 Olympic Bid Committee (1996); ATHOC (2003, 2004, 2005a, b); Beijing 2008 Olympic Games Bid Committee (2001); PyeongChang 2018 Olympic \& Paralympic Winter Games Bid Committee (2010); Sochi 2014 Bid Committee (2006); SOOC (2011, 2012); Torino Bid Committee (1998)

SUMMER: Many Olympic cities cannot use lotteries to fund their OCOG. Only Athens 2004 and Beijing 2008 were host cities that planned revenues from a lottery. Beijing 2008 planned one, but renounced it, or at least we could not find any data. The lottery for Athens 2004 could not be used to finance ATHOC, and the Greek government was obliged to pay these lost revenues.

WINTER: For the Olympic Winter Games, Turin 2006 and PyeongChang 2014 planned a lottery in their Candidature Files, but did not succeed. Only Sochi 2014 wanted to generate revenue through a lottery. Two years prior to the Games it wanted to increase the revenue by $75 \%$, but did not manage to receive revenues in the end.

The donations category is very contextual. This type of revenue could be a type of commitment. E.g. in PyeongChang, the telecom supplier was supposed to build the IBC and use it after the Games. Later the idea was dropped. but the telecom supplier was still bound to provide a subsidy to POCOG. 
Table 53 Olympic Games estimated and final revenues - donations

\begin{tabular}{llllllllll}
\hline Donations & $\mathbf{t}-\mathbf{8}$ & $\mathbf{t}-\mathbf{6}$ & $\mathbf{t}-\mathbf{5}$ & $\mathbf{t}-\mathbf{4}$ & $\mathbf{t}-\mathbf{3}$ & $\mathbf{t}-\mathbf{2}$ & $\mathbf{t}-\mathbf{1}$ & $\mathbf{f i n a l}$ & \\
\hline Max & $0 \%$ & & & & & & $-85 \%$ & $-60 \%$ & BEIJING \\
\hline Mean & $0 \%$ & & $21 \%$ & $17 \%$ & $-43 \%$ & $-65 \%$ & $-80 \%$ & \\
\hline Min & $0 \%$ & & $21 \%$ & $17 \%$ & $-43 \%$ & $-45 \%$ & $-99 \%$ & ATHENS \\
\hline $\begin{array}{l}\text { Oanpic } \\
\text { Winter }\end{array}$ & $0 \%$ & & $3643 \%$ & & & & & \\
Games & & & & & & & & & \\
\hline
\end{tabular}

Sources: Athens 2004 Olympic Bid Committee (1996); ATHOC (2003, 2004, 2005a, b); Beijing 2008 Olympic Games Bid Committee (2001); BOCOG (n. d., 2007); Rio 2016 Candidate City (2008); POCOG (2014, 2016, 2018); PyeongChang 2018 Olympic \& Paralympic Winter Games Bid Committee (2010); Salt Lake City Bid Committee (1994); SLOC (n. d., 2002); Torino Bid Committee (1998); Vancouver 2010 Candidate City (2002)

SUMMER: Donations are also a revenue source that is difficult to predict. Very often we could not find data about donations. Sydney 2000 and London 2012 did not anticipate donations when they created their first budget, and that did not change in the process. By contrast, Rio 2016 expected donations and then apparently could not generate any. Often we had no starting figure (as donations were not anticipated) or we had no final figure. The average is based only on the two cases and shows an $80 \%$ underrun.

WINTER: Here Turin 2006 and Sochi 2018 did not plan revenues. Vancouver 2010 was planning to receive donations when bidding, but did not mention this revenue in the remainder of the preparation progress. The two host cities that received donations averaged more than $1300 \%$. Salt Lake City 2002 had the most revenue overrun, with 2072\%, and followed by PyeongChang 2018with 664\%. However, these high percentages were caused by very low and conservative expectations.

The disposal of assets category is very much linked with the procurement and legacy strategy of the OCOG and the agreements with the government. If the OCOG rents most of its equipment, the disposal value is lower. If the OCOG buys the equipment and afterwards donates it to government entities, the revenue might be lower than expected (e.g. Beijing). The key learning is how early the OCOG incorporates its disposal and legacy strategy in its planning that will allow it to have an appropriate budget plan. 
Table 54 Olympic Games estimated and final revenues - disposal of assets

\begin{tabular}{llllllrrrl}
\hline $\begin{array}{l}\text { Disposal } \\
\text { of Assets }\end{array}$ & $\mathbf{t}-\mathbf{8}$ & $\mathbf{t}-\mathbf{6}$ & $\mathbf{t}-\mathbf{5}$ & $\mathbf{t}-\mathbf{4}$ & $\mathbf{t}-\mathbf{3}$ & $\mathbf{t}-\mathbf{2}$ & $\mathbf{t}-\mathbf{1}$ & \multicolumn{1}{c}{ final } & \\
\hline Max & & & & & & & $0 \%$ & $137 \%$ & SYDNEY \\
\hline Mean & $0 \%$ & & $19 \%$ & $6 \%$ & $-21 \%$ & $175 \%$ & $-44 \%$ & $4 \%$ & \\
\hline Min & $0 \%$ & & & & & & $-88 \%$ & $-73 \%$ & BEIJING \\
\hline Olympic & & & & & & & & & \\
Winter & $0 \%$ & & & & & & & $315 \%$ & SALT LAKE \\
Games & & & & & & & & & \\
\hline
\end{tabular}

Sources: Athens 2004 Olympic Bid Committee (1996); ATHOC (2005a, b); Beijing 2008 Olympic Games Bid Committee (2001); BOCOG (n. d., 2007); COJOPR (2016a, b); IOC Data; LOCOG (2008, 2009 2012); London 2012 Candidate City (2004); OCA (2002); Rio 2016 Candidate City (2008); SOCOG (2001, 2002); POCOG (2014, 2016, 2018); PyeongChang 2018 Olympic \& Paralympic Winter Games Bid Committee (2010); Salt Lake City Bid Committee (1994); SLOC (2002); Sochi 2014 Bid Committee (2006); Torino Bid Committee (1998); TOROC (2005); Vancouver 2010 Candidate City (2002)

SUMMER: Revenues from the disposal of assets are not too difficult to estimate as the average line shows that the final revenues were similar to the bid files. However, Sydney 2000 did not plan revenues until a year before the Games (overrun of 137\%). Beijing 2008, on the other hand, could not reach all the goals it wanted to achieve by selling assets (loss of 73\%).

WINTER: In their candidature files all hosts of the Olympic Winter Games wanted to generate revenues from the disposal of assets. In the end, only Salt Lake City 2002 included them in their revenue structure. The others may have taken it in "others". Salt Lake City 2002 had a revenue overrun of about 315\%. 
Table 55 Olympic Games estimated and final revenues - subsidies

\begin{tabular}{|c|c|c|c|c|c|c|c|c|c|}
\hline Subsidies & $t-8$ & $t-6$ & $t-5$ & $t-4$ & $t-3$ & $t-2$ & $t-1$ & final & \\
\hline \multirow{3}{*}{ 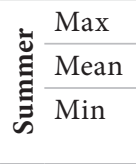 } & $0 \%$ & & $48 \%$ & $47 \%$ & $48 \%$ & & $106 \%$ & $143 \%$ & LONDON \\
\hline & $0 \%$ & & $48 \%$ & $20 \%$ & $48 \%$ & & $106 \%$ & $48 \%$ & \\
\hline & & & & & & & & $0 \%$ & $\begin{array}{l}\text { SYDNEY/ } \\
\text { ATHENS }\end{array}$ \\
\hline$\doteq \operatorname{Max}$ & $0 \%$ & & & $0 \%$ & & & & $1540 \%$ & SALT LAKE \\
\hline$\stackrel{\Xi}{J}$ Mean & $0 \%$ & & & $47 \%$ & $19 \%$ & $45 \%$ & $-44 \%$ & $593 \%$ & \\
\hline$>\operatorname{Min}$ & $0 \%$ & & & & $-59 \%$ & $-57 \%$ & $-44 \%$ & $-42 \%$ & SOCHI \\
\hline
\end{tabular}

Sources: Athens 2004 Olympic Bid Committee (1996); ATHOC (2005b); Beijing 2008 Olympic Games Bid Committee (2001); COJOPR (2016a); IOC Data; LOCOG (2008, 2009 2012); London 2012 Candidate City (2004); OCA (2002); Rio 2016 Candidate City (2008); Sydney Olympics Bid 2000 (1993); SOCOG (2002); POCOG (2014, 2016, 2018); PyeongChang 2018 Olympic \& Paralympic Winter Games Bid Committee (2010); Salt Lake City Bid Committee (1994); SLOC (n. d., 2002); Sochi 2014 Bid Committee (2006); SOOC (2011, 2012, 2013, 2014); Torino Bid Committee (1998); TOROC (2005); Vancouver 2010 Candidate City (2002); VANOC (2014)

SUMMER: Sydney 2000 and Athens 2004 did not expect to receive subsidies from the state, region or city. In the end, their budgets showed subsidies. By contrast, Beijing $2008^{21}$ and Rio $2016^{22}$ were planning to obtain subsidies, but they did not receive them. Only London 2012 had consistent recourse to subsidies, which eventually overran by $143 \%$. London's high subsidy revenue overrun explains the high average of $48 \%$ for the Olympic Games.

WINTER: All Olympic Winter Games OCOGs expected subsidies according to their candidature files. Turin 2006 did not get them. Sochi 2014 had a $42 \%$ revenue underrun, while the other cities had a revenue overrun. On average, subsidies led to a 593\% revenue overrun, with Salt Lake City 2002 having the highest $(1540 \%)$ due to low and conservative expectations.

21 Beijing 2008 had a successful commercial programme, so it did not use the government subsidies.

22 Rio 2016 tried to avoid the subsidies in order to maintain its private entity legal status. 
Table 56 Olympic Games estimated and final revenues - total

\begin{tabular}{llcccccccc}
\hline Total & $\mathbf{t}-\mathbf{8}$ & $\mathbf{t}-\mathbf{6}$ & $\mathbf{t}-\mathbf{5}$ & $\mathbf{t}-\mathbf{4}$ & $\mathbf{t}-\mathbf{3}$ & $\mathbf{t}-\mathbf{2}$ & $\mathbf{t}-\mathbf{1}$ & $\mathbf{f i n a l}$ & \\
\hline Max & $0 \%$ & $-8 \%$ & & & $52 \%$ & $67 \%$ & $63 \%$ & $72 \%$ & SYDNEY \\
\hline Mean & $0 \%$ & $-8 \%$ & $26 \%$ & $27 \%$ & $25 \%$ & $31 \%$ & $34 \%$ & $45 \%$ & \\
\hline Min & $0 \%$ & & & & & & $25 \%$ & $8 \%$ & BEIJING \\
\hline Max & $0 \%$ & $51 \%$ & & $110 \%$ & $96 \%$ & & & $119 \%$ & SALT LAKE \\
\hline Mean & $0 \%$ & $51 \%$ & & $65 \%$ & $31 \%$ & $9 \%$ & $18 \%$ & $43 \%$ & \\
\hline Min & $0 \%$ & & & & $-5 \%$ & $-9 \%$ & $-7 \%$ & $-3 \%$ & SOCHI \\
\hline
\end{tabular}

Sources: Athens 2004 Olympic Bid Committee (1996); ATHOC (2003, 2004, 2005a, b); Beijing 2008 Olympic Games Bid Committee (2001); BOCOG (n. d., 2007); COJOPR (2015, 2016a, b); IOC Data; LOCOG (2008, 2009, 2012); London 2012 Candidate City (2004); OCA (2002); Sydney Olympics Bid (1993); Rio 2016 Candidate City (2008); SOCOG (2001, 2002); POCOG (2014, 2016, 2018); PyeongChang 2018 Olympic \& Paralympic Winter Games Bid Committee (2010); Salt Lake City Bid Committee (1994); SLOC (n. d., 2002); Sochi 2014 Bid Committee (2006); SOOC (2011, 2012, 2013, 2014); Torino Bid Committee (1998); TOROC (2005); Vancouver 2010 Candidate City (2002); VANOC (2007, 2008, 2009, 2014)

SUMMER: When considering total revenues, all OCOGs achieved a revenue overrun over the eight years of preparation. The expectations of the cities were greatly exceeded. Sydney 2000 had the highest gain of $72 \%$, while the average overrun was about $45 \%$.

WINTER: For the Winter Games, all OCOGs but Sochi 2014 received more revenues than planned in their candidature files. On average, they were able to generate an additional 43\%. The highest revenue overrun was Salt Lake City 2002 with 119\%, and the only revenue underrun was for Sochi 2014 with 11\%. This was mainly caused by a high inflation rate and the exchange rate to the USD. 


\subsection{Expenditure Corridors by OCOG Category}

In the following section we will look at the corridors that can be seen in OCOG expenditure categories.

Table 57 Olympic Games estimated and final expenditures - venues

\begin{tabular}{llllllrrrl}
\hline Venues & $\mathbf{t}-\mathbf{8}$ & $\mathbf{t}-\mathbf{6}$ & $\mathbf{t}-\mathbf{5}$ & $\mathbf{t}-\mathbf{4}$ & $\mathbf{t}-\mathbf{3}$ & $\mathbf{t}-\mathbf{2}$ & $\mathbf{t}-\mathbf{1}$ & final & \\
\hline Max & $0 \%$ & $-8 \%$ & & & $89 \%$ & $181 \%$ & $163 \%$ & $203 \%$ & SYDNEY \\
\hline Mean & $0 \%$ & $-8 \%$ & $22 \%$ & $-19 \%$ & $-13 \%$ & $32 \%$ & $6 \%$ & $40 \%$ & \\
\hline Min & $0 \%$ & & & & & & $-78 \%$ & $-54 \%$ & BEIJING \\
\hline Max & $0 \%$ & & & & $-41 \%$ & $-46 \%$ & $-36 \%$ & $-33 \%$ & SOCHI \\
\hline Mean & $0 \%$ & & & $-3 \%$ & $-10 \%$ & $-1 \%$ & $-43 \%$ & $-52 \%$ & \\
\hline Min & $0 \%$ & & & & & & $-49 \%$ & $-81 \%$ & TURIN \\
\hline
\end{tabular}

Sources: Athens 2004 Olympic Bid Committee (1996); ATHOC (2003, 2004, 2005a, b); Beijing 2008 Olympic Games Bid Committee (2001); BOCOG (n. d., 2007); COJOPR (2015, 2016a, b); LOCOG (2008, 2009, 2012, 2013); London 2012 Candidate City (2004); OCA (2002); Rio 2016 Candidate City (2008); Sydney Olympics Bid (1993); SOCOG (2001, 2002); POCOG (2014, 2016, 2018); PyeongChang 2018 Olympic \& Paralympic Winter Games Bid Committee (2010); SLOC (1998); Sochi 2014 Bid Committee (2006); SOOC (2011, 2012, 2013, 2014); Torino Bid Committee (1998); TOROC (n. d., 2005); Vancouver 2010 Candidate City (2002); VANOC (2008)

The expenditures for venues show both cost overruns and cost underruns. For the operational expenditures and capital investments of facilities, Sydney 2000 had an overrun of $203 \%$. However, on average, expenditure on venues tends to have cost underruns. Athens 2004, Beijing 2008 and Rio 2016 reduced their costs during the preparations. This is also the result of the agreements concerning the split of responsibilities between the OCOG and government parties. One element is the ongoing optimisation of requirements, but another element is that some responsibilities are shifted to the government. Nevertheless, the average increase in expenditures over the eight years was around $40 \%$ for Olympic Games but minus $52 \%$ for Winter Games.

WINTER: All Winter Games OCOGs, except PyeongChang 2018 which is not finished yet, finally spent less than they had originally expected. Turin 2006 spent $81 \%$ less than planned. 
Table 58 Olympic Games estimated and final expenditures - workforce ${ }^{23}$

\begin{tabular}{lllrrrrrrl}
\hline Workforce & $\mathbf{t}-\mathbf{8}$ & $\mathbf{t}-\mathbf{6}$ & $\mathbf{t}-\mathbf{5}$ & $\mathbf{t}-\mathbf{4}$ & $\mathbf{t}-\mathbf{3}$ & $\mathbf{t}-\mathbf{2}$ & $\mathbf{t}-\mathbf{1}$ & $\mathbf{f i n a l}$ & \\
\hline Max & & & & $0 \%$ & $200 \%$ & $82 \%$ & & $179 \%$ & ATHENS \\
\hline Mean & $0 \%$ & $-8 \%$ & $154 \%$ & $15 \%$ & $121 \%$ & $23 \%$ & $-23 \%$ & $30 \%$ & \\
\hline Min & & & & & & & $0 \%$ & $-37 \%$ & BEIJING \\
\hline Max & & & & $0 \%$ & & & & $702 \%$ & SALT LAKE \\
\hline Mean & $0 \%$ & & & $32 \%$ & $11 \%$ & $-9 \%$ & $3 \%$ & $283 \%$ & \\
\hline Min & $0 \%$ & & & & $17 \%$ & $7 \%$ & $6 \%$ & $1 \%$ & SOCHI \\
\hline
\end{tabular}

Sources: ATHOC (2003, 2004, 2005a, b); BOCOG (n. d., 2007); COJOPR (2015, 2016a, b); LOCOG (2008, 2009, 2012, 2013); London 2012 Candidate City (2004); OCA (2002); Rio 2016 Candidate City (2008); Sydney Olympics Bid (1993); SOCOG (2001, 2002); POCOG (2014, 2016, 2018); PyeongChang 2018 Olympic \& Paralympic Winter Games Bid Committee (2010); SLOC (1998); Sochi 2014 Bid Committee (2006); SOOC (2011, 2012, 2013, 2014); Torino Bid Committee (1998); TOROC (n. d., 2005); Vancouver 2010 Candidate City (2002); VANOC (2008)

SUMMER: The figure on the left shows that, on average, the changes are great, but tend to be at $30 \%$ for the last two years. Athens 2004 had the highest expenditure increase, and started to calculate those only four years before the Games. The other host cities had moderate changes. Beijing 2008, for example, did not report the costs of the workforce separately until a year before the Games and then even underran that projection. BOCOG also didn't include all government staff in the workforce budget. Sydney 2000 and London 2012 also cut costs for the workforce.

WINTER: For the Olympic Winter Games, the changes are not as great. However, Salt Lake City 2002 did not show its workforce costs exploding in its Candidature File, which is why the first record was only four years before the Games were staged, and then the estimate was exceeded by $702 \%$. Sochi 2014 , on the other hand, only had a slight increase of 1\%. The cost overruns of Turin 2006 had a moderate $10 \%$ overrun. The five Games average, however, had a $283 \%$ overrun caused by Salt Lake City 2002.

23 The "workforce" category was presented inconsistently for the different Games editions. Some centralised those costs, whereas others decentralised them. As a result, there are strong fluctuations between the results. 
Table 59 Olympic Games estimated and final expenditures - technology

\begin{tabular}{llrrrrrrrl}
\hline Technology & $\mathbf{t}-\mathbf{8}$ & $\mathbf{t}-\mathbf{6}$ & $\mathbf{t}-\mathbf{5}$ & $\mathbf{t}-\mathbf{4}$ & $\mathbf{t}-\mathbf{3}$ & $\mathbf{t}-\mathbf{2}$ & $\mathbf{t}-\mathbf{1}$ & final & \\
\hline Max & $0 \%$ & & $-5 \%$ & $30 \%$ & $57 \%$ & & $60 \%$ & $72 \%$ & LONDON \\
\hline Mean & $0 \%$ & & $-5 \%$ & $15 \%$ & $11 \%$ & $1 \%$ & $17 \%$ & $16 \%$ & \\
\hline Min & & & & $0 \%$ & $4 \%$ & $-9 \%$ & $-12 \%$ & $-21 \%$ & ATHENS \\
\hline Max & $0 \%$ & & & & & & $145 \%$ & $277 \%$ & TURIN \\
\hline Mean & $0 \%$ & & & $3 \%$ & $5 \%$ & $4 \%$ & $53 \%$ & $72 \%$ & \\
\hline Min & & & & $0 \%$ & & & & $-22 \%$ & SALT LAKE \\
\hline
\end{tabular}

Sources: ATHOC (2003, 2004, 2005a, b); BOCOG (n. d., 2007); COJOPR (2015, 2016a, b); LOCOG (2008, 2009, 2012, 2013); London 2012 Candidate City (2004); OCA (2002); Rio 2016 Candidate City (2008); Sydney Olympics Bid (1993); SOCOG (2001, 2002); POCOG (2014, 2016, 2018); PyeongChang 2018 Olympic \& Paralympic Winter Games Bid Committee (2010); SLOC (1998); Sochi 2014 Bid Committee (2006); SOOC (2011, 2012, 2013, 2014); Torino Bid Committee (1998); TOROC (n. d., 2005); Vancouver 2010 Candidate City (2002); VANOC $(2007,2008,2009,2014)$

SUMMER: The development of the expenditures for technology is moderate. In addition to London 2012, which had the highest expenditure increase of $72 \%$, Sydney 2000 also had higher expenditures for technology. The other three cities had cost underruns. It should also be noted that technology costs are not as volatile as other categories. The IOC provides financial info about the key TOP technology partners like OMEGA and Atos because former bid cities used to completely miss out the cost of the key technology components. Apparently, these expenses can be estimated comparatively well. This is also evident from the only slight average cost increase of $16 \%$.

WINTER: Technology for the Olympic Winter Games was 72\% higher on average. Three OCOGs spent more than expected, but two were able to even save in this category. The highest overrun was for Turin 2006 (277\%), while Salt Lake City 2002 optimise its spending by $22 \%$. 
Table 60 Olympic Games estimated and final expenditures - services

\begin{tabular}{lllllrrrrl}
\hline Services & $\mathbf{t}-\mathbf{8}$ & $\mathbf{t}-\mathbf{6}$ & $\mathbf{t}-\mathbf{5}$ & $\mathbf{t}-\mathbf{4}$ & $\mathbf{t}-\mathbf{3}$ & $\mathbf{t}-\mathbf{2}$ & $\mathbf{t}-\mathbf{1}$ & \multicolumn{1}{l}{ final } & \\
\hline Max & $0 \%$ & $-8 \%$ & & & $240 \%$ & $301 \%$ & $305 \%$ & $103 \%$ & SYDNEY \\
\hline Mean & $0 \%$ & $-8 \%$ & $24 \%$ & $11 \%$ & $45 \%$ & $81 \%$ & $60 \%$ & $46 \%$ & \\
\hline Min & $0 \%$ & & & & & & $-14 \%$ & $9 \%$ & BEIJING \\
\hline Max & $0 \%$ & & & $-17 \%$ & & & & $712 \%$ & SALT LAKE \\
\hline Mean & $0 \%$ & & & $-14 \%$ & $-13 \%$ & $40 \%$ & $19 \%$ & $294 \%$ & \\
\hline Min & $0 \%$ & & & & $-20 \%$ & $-28 \%$ & $-19 \%$ & $-23 \%$ & SOCHI \\
\hline
\end{tabular}

Sources: Athens 2004 Olympic Bid Committee (1996); ATHOC (2003, 2004, 2005a, b); Beijing 2008 Olympic Games Bid Committee (2001); BOCOG (n. d., 2007); COJOPR (2015, 2016a, b); LOCOG (2008, 2009, 2012, 2013); London 2012 Candidate City (2004); OCA (2002); Rio 2016 Candidate City (2008); Sydney Olympics Bid (1993); SOCOG (2001, 2002); POCOG (2014, 2016, 2018); PyeongChang 2018 Olympic \& Paralympic Winter Games Bid Committee (2010); Salt Lake City Bid Committee (1994); SLOC (1998); Sochi 2014 Bid Committee (2006); SOOC (2011, 2012, 2013, 2014); Torino Bid Committee (1998); TOROC (n. d.); Vancouver 2010 Candidate City (2002); VANOC (2008)

SUMMER: For services, the mean expenditure increase was about $46 \%$. It should be noted that all OCOGs spent more on services than they originally planned. Sydney 2000 even spent twice as much as planned. In fact, a year before the Games, it had even planned four times higher expenditures. Beijing 2008 had the lowest cost increase with only $9 \%$.

WINTER: Expenditures for services also became more expensive for all Olympic Winter Games, except for Sochi 2014 (minus 23\%). A reason may be that location and market maturity has an impact on costs. The average change was much higher here, with 294\%. The highest expenditure increase was for Salt Lake City 2002, with $712 \%$.

In the marketing \& events category, the ceremonies and torch relay are also assumed, which are key fundamentals of accounting at the Olympic Games, under the responsibility of the OCOG, which makes a strategic decision on how much it wants to spend. 
Table 61 Olympic Games estimated and final expenditures - marketing \& events

\begin{tabular}{llllllllll}
\hline $\begin{array}{l}\text { Marketing \& } \\
\text { Events }\end{array}$ & $\mathbf{t}-\mathbf{8}$ & $\mathbf{t}-\mathbf{6}$ & $\mathbf{t}-\mathbf{5}$ & $\mathbf{t}-\mathbf{4}$ & $\mathbf{t}-\mathbf{3}$ & $\mathbf{t}-\mathbf{2}$ & $\mathbf{t}-1$ & final & \\
\hline Max & $0 \%$ & & $11 \%$ & $38 \%$ & $-6 \%$ & & $209 \%$ & $78 \%$ & LONDON \\
\hline Mean & $0 \%$ & $-8 \%$ & $11 \%$ & $22 \%$ & $-7 \%$ & $-11 \%$ & $80 \%$ & $32 \%$ & \\
\hline Min & $0 \%$ & $-8 \%$ & & & $-48 \%$ & $-55 \%$ & $-59 \%$ & $-46 \%$ & SYDNEY \\
\hline Max & $0 \%$ & & & & $354 \%$ & $53 \%$ & $381 \%$ & $437 \%$ & VANCOUVER \\
\hline Mean & $0 \%$ & & & $27 \%$ & $134 \%$ & $42 \%$ & $148 \%$ & $126 \%$ & \\
\hline Min & $0 \%$ & & & $19 \%$ & & & & $-23 \%$ & SALT LAKE \\
\hline
\end{tabular}

Sources: Athens 2004 Olympic Bid Committee (1996); ATHOC (2003, 2004, 2005a, b); Beijing 2008 Olympic Games Bid Committee (2001); BOCOG (n. d., 2007); COJOPR (2015, 2016a, b); LOCOG (2008, 2009, 2012, 2013); London 2012 Candidate City (2004); OCA (2002); Rio 2016 Candidate City (2008); Sydney Olympics Bid (1993); SOCOG (2001, 2002); POCOG (2014, 2016, 2018); PyeongChang 2018 Olympic \& Paralympic Winter Games Bid Committee (2010); Salt Lake City Bid Committee (1994); SLOC (1998); Sochi 2014 Bid Committee (2006); SOOC (2011, 2012, 2013, 2014); Torino Bid Committee (1998); TOROC (n. d., 2005); Vancouver 2010 Candidate City (2002); VANOC (2007, 2008, 2009, 2014)

SUMMER: There is quite a lot of variation in the marketing \& events category. Sydney 2000 cut expenditures in this category by 46\%. Athens 2004, Beijing 2008 and London 2012, on the other hand, spent more than they had indicated in their application documents. In 2011, London 2012 had a threefold expenditure overrun, but finally achieved $78 \%$. For marketing \& events, the average increase was $32 \%$. This is easy to explain because many marketing activities and the torch relay are often only planned well after winning a bid.

WINTER: Vancouver 2010 had cost overruns of $437 \%$ in the final budget. Apart from Sochi 2014 (minus 23\%), all other cities had overruns, the average being 126\%. In general, American cities have less marketing operation costs because they are in joint venture with the United States Olympic Committee. 
Table 62 Olympic Games estimated and final expenditures - administration \& coordination

\begin{tabular}{|c|c|c|c|c|c|c|c|c|c|c|}
\hline \multicolumn{2}{|c|}{$\begin{array}{l}\text { Administration } \\
\text { \& Coordination }\end{array}$} & $t-8$ & $t-6$ & $t-5$ & $t-4$ & $t-3$ & $t-2$ & $t-1$ & final & \\
\hline \multirow{3}{*}{ 岕 } & $\operatorname{Max}$ & $0 \%$ & $-8 \%$ & & & $343 \%$ & $294 \%$ & $253 \%$ & $481 \%$ & SYDNEY \\
\hline & Mean & $0 \%$ & $-8 \%$ & $33 \%$ & $11 \%$ & $96 \%$ & $144 \%$ & $95 \%$ & $153 \%$ & \\
\hline & Min & $0 \%$ & & & & & & $25 \%$ & $19 \%$ & BEIJING \\
\hline \multirow{3}{*}{ 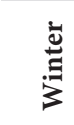 } & $\operatorname{Max}$ & $0 \%$ & & & & $-13 \%$ & $-16 \%$ & $-19 \%$ & $-10 \%$ & SOCHI \\
\hline & Mean & $0 \%$ & & & $21 \%$ & $9 \%$ & $22 \%$ & $-23 \%$ & $-29 \%$ & \\
\hline & Min & $0 \%$ & & & $-9 \%$ & & & & $-51 \%$ & SALT LAKE \\
\hline
\end{tabular}

Sources: Athens 2004 Olympic Bid Committee (1996); ATHOC (2003, 2004, 2005a, b); Beijing 2008 Olympic Games Bid Committee (2001); BOCOG (n. d., 2007); COJOPR (2015, 2016a, b); LOCOG (2008, 2009, 2012, 2013); London 2012 Candidate City (2004); OCA (2002); Rio 2016 Candidate City (2008); Sydney Olympics Bid (1993); SOCOG (2001, 2002); POCOG (2014, 2016, 2018); PyeongChang 2018 Olympic \& Paralympic Winter Games Bid Committee (2010); Salt Lake City Bid Committee (1994); SLOC (1998); Sochi 2014 Bid Committee (2006); SOOC (2011, 2012, 2013, 2014); Torino Bid Committee (1998); TOROC (n. d.); Vancouver 2010 Candidate City (2002); VANOC (2007, 2008, 2009, 2014)

SUMMER: Administration and coordination expenses were also higher than planned for all Games. On average, OCOGs spent 153\% more, with Sydney 2000 reaching a $481 \%$ expenditure overrun. That leads to the relatively high average figure of $70 \%$. The lowest cost increase was Beijing 2008 with 19\%.

WINTER: Unlike the Olympic Games, the Olympic Winter Games seem to be better planned and controlled in this category. All cities had cost underruns. The average cost reduction was $29 \%$. 
Table 63 Olympic Games estimated and final expenditures - total

\begin{tabular}{llllllllll}
\hline Total & $\mathbf{t}-\mathbf{8}$ & $\mathbf{t}-\mathbf{6}$ & $\mathbf{t}-\mathbf{5}$ & $\mathbf{t}-\mathbf{4}$ & $\mathbf{t}-\mathbf{3}$ & $\mathbf{t}-\mathbf{2}$ & $\mathbf{t}-\mathbf{1}$ & \multicolumn{1}{c}{ final } & \\
\hline Max & $0 \%$ & $-8 \%$ & & & $53 \%$ & $66 \%$ & $63 \%$ & $51 \%$ & SYDNEY \\
\hline Mean & $0 \%$ & $-8 \%$ & $26 \%$ & $27 \%$ & $27 \%$ & $36 \%$ & $31 \%$ & $33 \%$ & \\
\hline Min & $0 \%$ & & & & & & $25 \%$ & $4 \%$ & BEIJING \\
\hline Max & $0 \%$ & & & $70 \%$ & & & & $114 \%$ & SALT LAKE \\
\hline Mean & $0 \%$ & & & $45 \%$ & $10 \%$ & $16 \%$ & $18 \%$ & $45 \%$ & \\
\hline Min & $0 \%$ & & & & $-5 \%$ & $-9 \%$ & $-7 \%$ & $-6 \%$ & SOCHI \\
\hline
\end{tabular}

Sources: Athens 2004 Olympic Bid Committee (1996); ATHOC (2003, 2004, 2005a, b); Beijing 2008 Olympic Games Bid Committee (2001); BOCOG (n. d., 2007); COJOPR (2015, 2016a, b); LOCOG (2008, 2009, 2012, 2013); London 2012 Candidate City (2004); OCA (2002); Rio 2016 Candidate City (2008); Sydney Olympics Bid (1993); SOCOG (2001, 2002); POCOG (2014, 2016, 2018); PyeongChang 2018 Olympic \& Paralympic Winter Games Bid Committee (2010); Salt Lake City Bid Committee (1994); SLOC (1998); Sochi 2014 Bid Committee (2006); SOOC (2011, 2012, 2013, 2014); Torino Bid Committee (1998); TOROC (n. d., 2005); Vancouver 2010 Candidate City (2002); VANOC (2007, 2008, 2009, 2014)

For four out of five of the last Olympic Games we observed expenditure overruns. The five Games average was 33\%, with the maximum overrun of 51\% for Sydney 2000. The five Games average for Winter Games was about $45 \%$. Salt Lake City 2002 had the biggest changes (114\%), but Sochi 2014 only $-6 \%$.

\subsection{Non-OCOG Cost Corridors at Olympic Games}

The following section will provide the cost changes for different venues. We will look at the venues in our "basket" but differentiate between the Olympic Games and Olympic Winter Games because the size of the venues and the venues themselves are different. 
Table 64 Olympic Games estimated and final non-OCOG costs - Olympic Stadium

\begin{tabular}{lllllrrrrr}
\hline $\begin{array}{l}\text { Olympic } \\
\text { Stadium }\end{array}$ & $\mathbf{t}-\mathbf{8}$ & $\mathbf{t}-\mathbf{6}$ & $\mathbf{t}-\mathbf{5}$ & $\mathbf{t}-\mathbf{4}$ & $\mathbf{t}-\mathbf{3}$ & $\mathbf{t}-\mathbf{2}$ & $\mathbf{t}-\mathbf{1}$ & final & \\
\hline Max & $0 \%$ & $67 \%$ & & & & $79 \%$ & $44 \%$ & $40 \%$ & LONDON \\
\hline Mean & $0 \%$ & $67 \%$ & & & & $10 \%$ & $-9 \%$ & $-11 \%$ & \\
\hline Min & $0 \%$ & & & & & $-60 \%$ & $-62 \%$ & $-61 \%$ & SYDNEY \\
\hline
\end{tabular}

Sources: Camara dos Deputados (2017); DCMS (2012a, b); House of Commons (2010); London 2012 Candidate City (2004); NSW (2002); OCA (1999, 2002); Rio 2016 Candidate City (2008); Sydney Olympics 2000 Bid Limited (1993); The Audit Office (1999, 2002)

Many media reports say it is surprising that the costs (governmental share) for the Olympic stadiums were on average $11 \%$ lower than announced in the candidature files. However, what may have an influence here is that we found only three cities where the costs were properly estimated in the candidature. However, a generalisation is not possible from this because Athens 2004 and Beijing 2008 had cost overruns which are not displayed transparently enough.

Based on solid facts and considering inflation we can state that Sydney 2000 had lower costs by $61 \%$. London 2012 spent $40 \%$ more for the construction of its Olympic Stadium.

Table 65 Olympic Games estimated and final non-OCOG costs - swimming pool

\begin{tabular}{|c|c|c|c|c|c|c|c|c|c|}
\hline Swimming Pool & $\mathrm{t}-8$ & $t-6$ & $t-5$ & $t-4$ & $t-3$ & $t-2$ & $t-1$ & final & \\
\hline $\operatorname{Max}$ & $0 \%$ & $178 \%$ & & & & $242 \%$ & $225 \%$ & $216 \%$ & LONDON \\
\hline Mean & $0 \%$ & $178 \%$ & & & & $121 \%$ & $225 \%$ & $105 \%$ & ( 2 cities) \\
\hline Min & & & & & & $0 \%$ & & $-6 \%$ & SYDNEY \\
\hline
\end{tabular}

Sources: Camara dos Deputados (2017); DCMS (2012a, b); House of Commons (2010); Kao (2016); London 2012 Candidate City (2004); NSW (2002); OCA (1999, 2002); Rio 2016 Candidate City (2008); The Audit Office $(1999,2002)$

For the construction of swimming pools, we also gathered reliable data only from three Games. Regarding the public investments in this venue, London 2012 had the highest increase (216\%), while Sydney 2000 constructed its pool even cheaper than its projection two years before the Games. On average, the construction of a swimming pool is $105 \%$ more expensive than planned. 
Table 66 Olympic Games estimated and final non-OCOG costs - multipurpose hall

\begin{tabular}{lccccccccc}
\hline Multipurpose Hall & $\mathbf{t}-\mathbf{8}$ & $\mathbf{t}-\mathbf{6}$ & $\mathbf{t}-\mathbf{5}$ & $\mathbf{t}-\mathbf{4}$ & $\mathbf{t}-\mathbf{3}$ & $\mathbf{t}-\mathbf{2}$ & $\mathbf{t}-\mathbf{1}$ & final & \\
\hline Max & $0 \%$ & & & & & $106 \%$ & $81 \%$ & $75 \%$ & SYDNEY \\
\hline Mean & $0 \%$ & $120 \%$ & & & $106 \%$ & $66 \%$ & $61 \%$ & \\
\hline Min & $0 \%$ & $120 \%$ & & & & $50 \%$ & $47 \%$ & LONDON \\
\hline
\end{tabular}

Sources: DCMS (2012a, b); London 2012 Candidate City (2004); NSW (2002); OCA (1999, 2002); Sydney Olympics 2000 Bid Limited (1993); The Audit Office $(1999,2002)$

The multipurpose hall is usually the main Olympic facility. We could find valid data for two Games only. Thus the average here is a $61 \%$ cost overrun calculated from Sydney (75\%) and London (47\%).

Table 67 Olympic Games estimated and final non-OCOG costs - velodrome

\begin{tabular}{|c|c|c|c|c|c|c|c|c|c|}
\hline Velodrome & $t-8$ & $t-6$ & $t-5$ & $t-4$ & $t-3$ & $t-2$ & $t-1$ & final & \\
\hline $\operatorname{Max}$ & $0 \%$ & & & & & $563 \%$ & $539 \%$ & $535 \%$ & SYDNEY \\
\hline Mean & $0 \%$ & $138 \%$ & & & & $391 \%$ & $360 \%$ & $359 \%$ & (2 cities) \\
\hline Min & $0 \%$ & $138 \%$ & & & & $218 \%$ & $181 \%$ & $182 \%$ & LONDON \\
\hline
\end{tabular}

Sources: Camara dos Deputados (2017); DCMS (2012a, b); House of Commons (2010); Kao (2016); London 2012 Candidate City (2004); NSW (2002); OCA (1999, 2002); Rio 2016 Candidate City (2008); Sydney Olympics 2000 Bid Limited (1993); The Audit Office (1999, 2002)

In the three reliable data sets, we found an average cost overrun of $359 \%$ for the velodrome. In all host cities, the costs were higher than originally planned, in Sydney 2000 more than six fold and London 2012 182\%.

Table 68 Olympic Games estimated and final non-OCOG costs - Olympic Village

\begin{tabular}{|c|c|c|c|c|c|c|c|c|c|}
\hline Olympic Village & $t-8$ & $t-6$ & $t-5$ & $t-4$ & $t-3$ & $t-2$ & $t-1$ & final & \\
\hline Max & $0 \%$ & & & & & $127 \%$ & & $157 \%$ & SYDNEY \\
\hline Mean & $0 \%$ & & & & & $127 \%$ & $1 \%$ & $45 \%$ & \\
\hline Min & $0 \%$ & & & & & & & $-27 \%$ & ATHENS \\
\hline
\end{tabular}

Sources: Athens 2004 Olympic Bid Committee (1996); Camara dos Deputados (2017); DCMS (2012a, b); Kasimati (2015); London 2012 Candidate City (2004); NSW (2002); OCA (2002); Rio 2016 Candidate City (2008); Sydney Olympics 2000 Bid Limited (1993); The Audit Office $(1999,2002)$ 
The only host that built the Olympic Village cheaper than planned was Athens 2004 (minus 27\%). All others had cost overruns with an average of $45 \%$. The highest cost overrun was in Sydney 2000 at $157 \%$.

For the IBC/MPC, we had data only from London 2012, which had a cost overrun of $103 \%$.

Table 69 Olympic Games estimated and final non-OCOG costs - total

\begin{tabular}{llllllllll}
\hline Total & $\mathbf{t}-\mathbf{8}$ & $\mathbf{t}-\mathbf{6}$ & $\mathbf{t}-\mathbf{5}$ & $\mathbf{t}-\mathbf{4}$ & $\mathbf{t}-\mathbf{3}$ & $\mathbf{t}-\mathbf{2}$ & $\mathbf{t}-\mathbf{1}$ & final & \\
\hline Max & $0 \%$ & & & & & $43 \%$ & & $56 \%$ & SYDNEY \\
\hline Mean & $0 \%$ & $85 \%$ & & & & $82 \%$ & $42 \%$ & $50 \%$ & \\
\hline Min & $0 \%$ & $85 \%$ & & & & $120 \%$ & $42 \%$ & $43 \%$ & LONDON \\
\hline
\end{tabular}

Sources: Camara dos Deputados (2017); DCMS (2012a, b); House of Commons (2010); Kasimati (2015); London 2012 Candidate City (2004); NSW (2002); OCA (1999, 2002); Rio 2016 Candidate City (2008); Sydney Olympics 2000 Bid Limited (1993); The Audit Office (1999, 2002)

The overall cost overruns were calculated as an average of the available data. Two out of two ${ }^{24}$ host cities had cost overruns. Sydney 2000, with 56\%, had the highest overrun, London actually spent $43 \%$ more than planned. Finally, it can be stated that the construction of sports facilities is about $50 \%$ higher than indicated in the candidature file.

24 We weren't able to find data for Beijing 2008 and had to use different venues for Athens 2004 because nearly all of our elected venues had no capital investments at the stage of the Candidature File. Similarly, as there is no final budget yet for the Games in Rio, we were unable to show any final figures for them. 


\subsection{Non-OCOG Cost Corridors at Olympic Winter Games}

Table 70 Olympic Winter Games estimated and final non-OCOG costs Olympic stadium

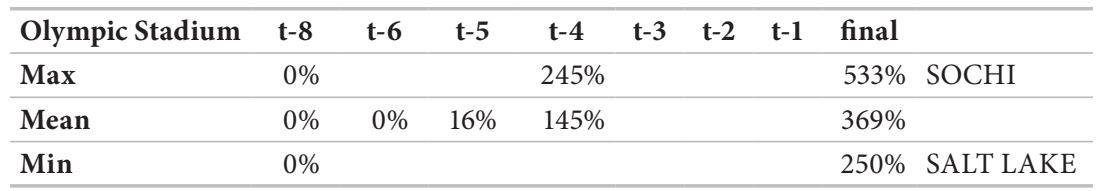

Sources: Anti-Corruption Foundation (n. d.); Aumüller (2014); British Columbia Olympic and Paralympic Winter Games Secretariat (2004); IOC Data; Partnerships British Columbia (2007); Salt Lake City Bid Committee (1994); SLOC (2001); Sochi 2014 Bid Committee (2006); SOOC (2010); VANOC (2010a, b)

The Olympic stadiums for the Olympic Winter Games became on average 369\% more expensive. Turin 2006 used an existing stadium for its Games, for which no investment was needed. PyeongChang 2018 did not plan to build a new stadium when setting the budget. Sochi 2014 had the highest cost overruns for the Olympic Stadium (533\%) and the lowest was in Salt Lake (250\%). These results show that the Olympic stadium became significantly more expensive at the Olympic Winter Games.

Table 71 Olympic Winter Games estimated and final non-OCOG costs ski jumping hill

\begin{tabular}{|c|c|c|c|c|c|c|c|c|c|}
\hline Ski Jumping Hill & $t-8$ & $t-6$ & $t-5$ & $t-4$ & $t-3$ & $t-2$ & $t-1$ & final & \\
\hline $\operatorname{Max}$ & $0 \%$ & & & $37 \%$ & & & & $286 \%$ & SOCHI \\
\hline Mean & $0 \%$ & $-7 \%$ & $-1 \%$ & $19 \%$ & $0 \%$ & & & $94 \%$ & \\
\hline Min & $0 \%$ & & & & & & & $-3 \%$ & TURIN \\
\hline
\end{tabular}

Sources: Anti-Corruption Foundation (n. d.); Aumüller (2014); Bottero et al. (2012); British Columbia Olympic and Paralympic Winter Games Secretariat (2004); Partnerships British Columbia (2007); Sochi 2014 Bid Committee (2006); SOOC (2010); Torino Bid Committee (1998); Vancouver 2010 Candidate City (2002); VANOC (2007, 2010a, b)

The construction of a ski jumping hill seems to be easier to plan and calculate. Only for Sochi 2014 did the originally planned costs have overruns (268\%). As with the Olympic Stadium, PyeongChang 2018 did not plan to build a ski jumping hill, and therefore no figures from the planning stage were available. The five-Games average for the construction of a ski jumping hill was a $94 \%$ cost overruns. 
Table 72 Olympic Winter Games estimated and final non-OCOG costs - sliding centre

\begin{tabular}{llllllllll}
\hline Sliding Centre & $\mathbf{t}-\mathbf{8}$ & $\mathbf{t}-\mathbf{6}$ & $\mathbf{t}-\mathbf{5}$ & $\mathbf{t}-\mathbf{4}$ & $\mathbf{t}-\mathbf{3}$ & $\mathbf{t}-\mathbf{2}$ & $\mathbf{t}-\mathbf{1}$ & $\mathbf{f i n a l}$ & \\
\hline Max & $0 \%$ & $-7 \%$ & $31 \%$ & $59 \%$ & $62 \%$ & & $55 \%$ & VANCOUVER \\
\hline Mean & $0 \%$ & $-7 \%$ & $31 \%$ & $16 \%$ & $62 \%$ & $26 \%$ & $20 \%$ & \\
\hline Min & $0 \%$ & & & $-27 \%$ & & & $-20 \%$ & SALT LAKE \\
\hline
\end{tabular}

Sources: Anti-Corruption Foundation (n. d.); Aumüller (2014); Bottero et al. (2012); British Columbia Olympic and Paralympic Winter Games Secretariat (2004); Partnerships British Columbia (2007); PyeongChang 2018 Olympic \& Paralympic Winter Games Bid Committee (2010); Roche (1994), Sochi 2014 Bid Committee (2006); SOOC (2010); Torino Bid Committee (1998); Vancouver 2010 Candidate City (2002); VANOC (2007, 2010a, b)

The construction of the Salt Lake City 2002 sliding centre showed cost underruns (20\%), while the five-Games average is a cost overrun of $20 \%$. Sochi 2014 was also cheaper than planned. Vancouver 2010 had the highest cost overrun at 55\%.

Table 73 Olympic Winter Games estimated and final non-OCOG costs - ice stadium

\begin{tabular}{llllllllll}
\hline Ice Stadium & $\mathbf{t}-\mathbf{8}$ & $\mathbf{t}-\mathbf{6}$ & $\mathbf{t}-\mathbf{5}$ & $\mathbf{t}-\mathbf{4}$ & $\mathbf{t}-\mathbf{3}$ & $\mathbf{t}-\mathbf{2}$ & $\mathbf{t}-\mathbf{1}$ & $\mathbf{f i n a l}$ & \\
Max & $0 \%$ & & & & & & & $53 \%$ & SALT LAKE \\
\hline Mean & $0 \%$ & $-19 \%$ & $-17 \%$ & $2 \%$ & $-20 \%$ & & $-3 \%$ & $-4 \%$ & \\
\hline Min & $0 \%$ & & & & & & & $-26 \%$ & TURIN \\
\hline
\end{tabular}

Sources: Anti-Corruption Foundation (n. d.); Aumüller (2014); Bottero et al. (2012); British Columbia Olympic and Paralympic Winter Games Secretariat (2004); Partnerships British Columbia (2007); PyeongChang 2018 Olympic \& Paralympic Winter Games Bid Committee (2010); Salt Lake City Bid Committee (1994); SLOC (2001); Sochi 2014 Bid Committee (2006); SOOC (2010); Torino Bid Committee (1998); Vancouver 2010 Candidate City (2002); VANOC $(2007,2010 a, b)$

The ice stadiums have mainly shown cost underruns over the eight years (- the five-Games average is minus 4\%). The only overrun was 53\% for Salt Lake, while Turin 2006 was able to reduce costs by $26 \%$. 
Table 74 Olympic Winter Games estimated and final non-OCOG costs Olympic Village

\begin{tabular}{|c|c|c|c|c|c|c|c|}
\hline Olympic Village & $t-8 \quad t-6$ & $t-5$ & $t-4$ & $t-3$ & $\mathrm{t}-2$ & $t-1$ & final \\
\hline $\operatorname{Max}$ & $0 \%$ & & $625 \%$ & & & & $471 \%$ SOCHI \\
\hline Mean & $0 \%$ & $14 \%$ & $319 \%$ & $12 \%$ & & $-57 \%$ & $179 \%$ \\
\hline Min & $0 \%$ & $14 \%$ & $13 \%$ & $12 \%$ & & & $12 \%$ VANCOUVER \\
\hline
\end{tabular}

Sources: Bottero et al. (2012); British Columbia Olympic and Paralympic Winter Games Secretariat (2004); Hong (2017); Müller (2014); Partnerships British Columbia (2007), PyeongChang 2018 Olympic \& Paralympic Winter Games Bid Committee (2010); Salt Lake City Bid Committee (1994); SLOC (2001); Sochi 2014 Bid Committee (2006); SOOC (2010); Torino Bid Committee (1998); Vancouver 2010 Candidate City (2002); VANOC (2007, 2010a, b)

Due to master plan changes for Sochi 2014, the costs for the Olympic Village changed dramatically and ended up being five times more expensive than planned. Vancouver managed the construction of the Olympic Village well and ended with a 12\% cost overrun. Due to Sochi 2014, the average of cost overruns for the Villages was 179\%.

Table 75 Olympic Winter Games estimated and final non-OCOG costs - IBC/MPC

\begin{tabular}{lccccccccc}
\hline IBC \& MPC & $\mathbf{t}-\mathbf{8}$ & $\mathbf{t}-\mathbf{6}$ & $\mathbf{t}-\mathbf{5}$ & $\mathbf{t}-\mathbf{4}$ & $\mathbf{t}-\mathbf{3}$ & $\mathbf{t}-\mathbf{2}$ & $\mathbf{t}-\mathbf{1}$ & $\mathbf{f i n a l}$ & \\
\hline Max & $0 \%$ & & & & & & & $-11 \%$ & SALT LAKE \\
\hline Mean & $0 \%$ & & & & & & $71 \%$ & $-18 \%$ & \\
\hline Min & $0 \%$ & & & & & & & $-25 \%$ & TURIN \\
\hline
\end{tabular}

Sources: Bottero et al. (2012); British Columbia Olympic and Paralympic Winter Games Secretariat (2004); Fay (2018); IOC Data; PyeongChang 2018 Olympic \& Paralympic Winter Games Bid Committee (2010); Salt Lake City Bid Committee (1994); Torino Bid Committee (1998)

Salt Lake City 2002 had a decrease of $11 \%$ for its IBC/MPC. Turin was also able to save some money from the projected costs (25\%). On average, the IBC/MPC was cheaper than planned in the candidature files (18\%). 
Table 76 Olympic Winter Games estimated and final non-OCOG costs - total

\begin{tabular}{|c|c|c|c|c|c|c|c|c|c|}
\hline Total & $t-8$ & $t-6$ & $t-5$ & $\mathrm{t}-4$ & $t-3$ & $t-2$ & $t-1$ & final & \\
\hline $\operatorname{Max}$ & $0 \%$ & & & $175 \%$ & & & & $178 \%$ & SOCHI \\
\hline Mean & $0 \%$ & $-8 \%$ & $11 \%$ & $95 \%$ & $12 \%$ & & $-26 \%$ & $60 \%$ & \\
\hline Min & $0 \%$ & $-8 \%$ & $11 \%$ & $14 \%$ & $12 \%$ & & & $13 \%$ & VANCOUVER \\
\hline
\end{tabular}

Sources: Anti-Corruption Foundation (n. d.); Aumüller (2014); Bottero et al. (2012); British Columbia Olympic and Paralympic Winter Games Secretariat (2004); Fay (2018); Hong (2017); IOC Data; Müller (2014); Partnerships British Columbia (2007); PyeongChang 2018 Olympic \& Paralympic Winter Games Bid Committee (2010); Roche (1994); Salt Lake City Bid Committee (1994); SLOC (2001); Sochi 2014 Bid Committee (2006); SOOC (2010); Torino Bid Committee (1998); Vancouver 2010 Candidate City (2002); VANOC (2007, 2010a, b)

For the Olympic Winter Games, the average cost overrun of venues in our basket was around $60 \%$. All host cities ${ }^{25}$ had cost overruns. The cost overruns of Salt Lake City 2002, Turin 2006 and Vancouver 2010 were at a moderate 13-28\% though. The highest cost overrun was for Sochi 2014, with 178\%.

\subsection{Summary of Costs and Revenues of Olympic Games Seperated by Categories}

In considering the various categories, as well as their most positive and negative manifestations, certain differences arise.

In terms of revenue, the IOC contribution is relatively stable. Since Vancouver 2010, this has been a fixed amount that will be paid out in instalments from four years before the Games onwards. Sources of error are therefore to be looked for in the candidature file, as there was possibly a wrong estimated exchange rate and/or level of inflation used. In the earlier years, from Sydney 2000 to Beijing 2008, the amount was a percentage of the sale of TV rights and could change over time due to the late sale of contracts. The revenue from the TOP sponsorship can be significantly higher (Salt Lake City 2002, Athens 2004) and always - with the exception of Sochi 2014 - led to a revenue overrun. Even higher revenues could be achieved in all cases by national sponsors - Beijing 2008 even received almost five times its expected

25 PyeongChang 2018 was just running during our data collection, so there are no final figures for PyeongChang, but the collected data influenced the mean during the preparation phase. 
revenues. However, a closer look has to be taken on whether the sponsors are state owned, and therefore the sponsorships are indirect subventions. In contrast, revenue from ticket sales is very difficult to predict. Nevertheless, the Games usually create a revenue overrun. In comparing Olympic Games and Olympic Winter Games, the overrun is lower for winter. The revenues of the licensing category are not very predictable, but lead on average to additional revenue. A barely used and seemingly outdated category is the lottery. Looking at the 10 Games, not a single host city actually generated revenues through a lottery. Subsidies are not used everywhere, but we also found large changes here and almost always came to a revenue overrun. A big difference between the Olympic Games and the Olympic Winter Games can be seen in donations. While donations for the Olympic Games are overestimated, they are underestimated for the Olympic Winter Games. The revenue from the disposal of assets can certainly increase, but Winter Games also seem to be more effective than Summer. As previously written, all Games - except Sochi 2014 - had a revenue overrun. Salt Lake City 2002 had the highest revenue overrun of 119\%.

Looking at the expenditures, many categories show differences between the Olympic Winter Games and the Olympic Games. In the venues, and administration and coordination categories, spending at the Olympic Games is changing, whereas for technology and services the fluctuations for the Olympic Winter Games are larger. The categories in which the Olympic Winter Games had cost underruns were venues and administration and coordination. Higher spending is often recorded in the workforce and service categories. The workforce and administration categories are most often estimated with too low costs because the organisation and rapid growth of the OCOG is often underestimated. In contrast, marketing and events is a category in which savings occur, but also cost overruns. Considering all expenditures, the corridor is smaller for the Summer Games than for the Winter Games. This suggests that the costs are more predictable for the Olympic Games.

Regarding the non-OCOG budgets, many Olympic Games venues show severe cost overruns. The swimming pool is on average $105 \%$ more costly, the multipurpose hall $61 \%$ and the velodrome $359 \%$. Among these venues only the swimming pool for Sydney 2000 was cheaper than planned. The cost of the Olympic stadium is very much dependent on whether an existing stadium can be used after modernisation or if a new construction is needed. A new construction often ends with a cost overrun. The Olympic Village can have cost underruns, such as for Athens 2004, but in general cost overruns have to be expected for this mega venue as well. In general, the estimate of the Olympic Village and the IBC/MPC is very important, because they make up the largest part of the overall costs. Thus they highly influence the total percentage of our basket. On average, summer venues are 50\% more expensive than planned. 
The Olympic Winter Games also have great cost overruns. The Olympic stadiums were on average $369 \%$ more expensive, the ski jumping hills $94 \%$, the sliding centres $20 \%$ and the Olympic Villages $179 \%$. The sliding centre's corridor is very small, and the ski jumping hill and Olympic Village are much larger. It is interesting that two venues had cost underruns. The ice stadiums (-4\%) and IBC/MPC (-18\%) were both on average cheaper than planned. Despite this, the construction of venues had an overall average of a $60 \%$ cost overrun.

Open Access This chapter is licensed under the terms of the Creative Commons Attribution 4.0 International License (http://creativecommons.org/licenses/by/4.0/), which permits use, sharing, adaptation, distribution and reproduction in any medium or format, as long as you give appropriate credit to the original author(s) and the source, provide a link to the Creative Commons licence and indicate if changes were made.

The images or other third party material in this chapter are included in the chapter's Creative Commons licence, unless indicated otherwise in a credit line to the material. If material is not included in the chapter's Creative Commons licence and your intended use is not permitted by statutory regulation or exceeds the permitted use, you will need to obtain permission directly from the copyright holder. 